Canadian

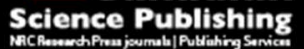

Canadian Journal of Civil Engineering Revue canadienne de génie civil

\title{
Reliability Consistent Mitigation Criteria for Corrosion Defects on Natural Gas Transmission Pipelines
}

\begin{tabular}{|r|l|}
\hline Journal: & Canadian Journal of Civil Engineering \\
\hline Manuscript ID & cjce-2015-0232.R1 \\
\hline Manuscript Type: & Article \\
\hline Date Submitted by the Author: & 31-Aug-2015 \\
\hline Complete List of Authors: & $\begin{array}{l}\text { Zhou, Wenxing; The University of Western Ontario } \\
\text { Siraj, Tammeen; The University of Western Ontario, Civil and } \\
\text { Environmental Engineering } \\
\text { Gong, Changqing; The University of Western Ontario, Civil and } \\
\text { Environmental Engineering }\end{array}$ \\
\hline Keyword: & Struct.Eng. \& Constr.Mate, reliability analyses < Struct.Eng. \& Constr.Mate \\
\hline &
\end{tabular}




\title{
Reliability Consistent Mitigation Criteria for Corrosion Defects on Natural Gas Transmission Pipelines
}

\author{
W. Zhou ${ }^{1}$, T. Siraj ${ }^{2}$ and C. Gong ${ }^{2}$
}

1. Corresponding author, Associate Professor, Department of Civil and Environmental Engineering, The University of Western Ontario, 1151 Richmond Street, London, ON N6A 5B9, Email: wzhou@eng.uwo.ca; Tel: 519-661-2111 x 87931; Fax: 519-667-3779.

2. PhD Candidate, Department of Civil and Environmental Engineering, The University of Western Ontario, London, ON N6A 5B9

Word count: approximately 9000 word equivalents 


\begin{abstract}
This article deals with reliability-based mitigation of metal-loss corrosion defects on steel natural gas transmission pipelines. The failure pressure ratios (FPRs) and probabilities of burst associated with corrosion defects with various sizes on representative gas pipelines are evaluated using the ASME B31G Modified model and first-order reliability method (FORM). The pipelines considered have different values of the maximum operating pressure, steel grade, wall thickness, outside diameter and utilization factor. The analysis results suggest that FPR and the reliability index corresponding to the probability of burst follow a linear relationship for pipelines with the same utilization factor. Based on the analysis results, linear regression equations that relate FPR to the reliability index are developed for pipelines with different utilization factors. The equation can be employed to determine the threshold FPR corresponding to a target reliability index (or allowable probability of burst) for a given utilization factor to identify critical corrosion defects for mitigation. This study will facilitate the risk- and reliability-based corrosion management of gas transmission pipelines.
\end{abstract}

Keyword: Gas transmission pipeline; Metal-loss corrosion; probability of burst; reliability index; failure pressure ratio, and utilization factor 


\section{Introduction}

Metal-loss corrosion is one of the leading causes for failures of buried steel oil and gas transmission pipelines (Nessim et al. 2009). Corrosion defects compromise the ability of pipelines to contain the internal pressure. A corroded pipeline will burst due to its internal pressure if the depth (in the through-pipe wall thickness direction) and length (in the pipeline longitudinal direction) of the corrosion defect are sufficiently large. Many empirical or semiempirical burst pressure capacity models for corroded pipelines have been developed in the past, for example, the well known ASME B31G Modified, DNV and PCORRC models (Zhou and Huang 2012). Although in various forms, these models generally are functions of the depth and length of the corrosion defect, pipe geometry (i.e. diameter and wall thickness) and material strength (e.g. yield strength, tensile strength or flow stress).

To manage the structural integrity of pipelines with respect to corrosion, pipeline engineers typically use the high-resolution in-line inspections (ILI) tools to periodically detect, locate and size the corrosion defects. Based on the ILI-reported sizes of the defects, burst pressure capacity models are employed to compute the capacities of the pipeline at the locations of the defects. A failure pressure ratio (FPR) for each defect is then evaluated as the ratio between the burst pressure capacity of the pipeline evaluated at the defect and maximum operating pressure (MOP) of the pipeline. Finally, those defects that have FPRs less than a pre-selected threshold FPR (e.g. 1.1 or 1.25) are deemed critical and subsequently mitigated through field excavation and repair. There is inconsistency in the selection of the threshold FPR in the current practice (Kariyawasam and Huang 2014). For example, ASME B31.8S (ASME 2010) recommends a threshold FPR of 1.1 for all gas pipelines, whereas the Canadian standard CSA Z662 (CSA 2011) recommends different threshold FPRs for gas pipelines in different class 
locations (the meaning of the class location is explained in the next section), e.g. threshold FRPs of 1.25, 1.39, 1.79 and 2.27 for Classes 1, 2, 3 and 4 pipelines, respectively.

Many uncertainties are involved in the pipeline corrosion management: the ILI tool is imperfect and associated with measurement errors; the actual geometric and material properties of the pipeline are uncertain, and the burst pressure capacity models are not perfectly accurate and therefore involve model errors. As a result, the reliability-based corrosion management is being increasingly adopted by pipeline operators because it provides a rationale framework to deal with the aforementioned uncertainties. One desirable outcome of the reliability-based corrosion management is to identify critical corrosion defects for mitigation based on consistent levels of the probability of burst; that is, a given corrosion defect will be mitigated if the probability of burst of the pipeline at the defect exceeds a predefined allowable probability of burst. Questions therefore arise as to the implied reliability levels associated with the currently-used threshold FPRs. Furthermore, because it may not be practical to require pipeline engineers to evaluate the probability of burst corresponding to each individual defect, a practical means to achieve reliability-consistent mitigations of corrosion defects is to determine the threshold FPR corresponding to a given allowable probability of burst. Such a study, which is somewhat similar to the calibration of the load and resistance factors for the design of buildings and bridges (e.g. Bartlett et al. 2003; Nowak 1995), however has not been reported in the literature.

The objectives of the work reported in this paper were to 1) investigate the implied reliability levels associated with the threshold FPR values employed in the current corrosion mitigation practice and 2) determine the threshold FPR levels corresponding to different allowable probabilities of burst to facilitate the reliability-consistent corrosion mitigation. The study 
was focused on natural gas transmission pipelines designed according to the Canadian Standards Association (CSA) Z662-11: Oil and Gas Pipeline Systems (CSA 2011). Liquid transmission pipelines were excluded because of a lack of probabilistic characteristics of the internal pressure in the literature. A set of representative gas pipelines with different values of the outside diameter, steel grade, operating pressure and wall thickness were developed. The ASME B31G Modified model (Kiefner and Vieth 1989), which is widely used in the industry to predict burst capacities of corroded pipelines, was employed to evaluate FPRs for the analysis cases with corrosion defects of various sizes, and also incorporated in the firstorder reliability method (FORM) (Melchers 1999; Low and Tang 1997, 2007) to evaluate the corresponding probabilities of burst. The uncertainties in the defect sizes, pipe geometric and material properties, internal pressure and accuracy of the B31G Modified model were considered in the reliability analysis.

The rest of the paper is organized as follows. The next section briefly describes the design of gas transmission pipelines according to CSA Z662, followed by the description of the B31G Modified model and determination of FPR. After that, the analysis cases, methodology for the reliability analysis and probabilistic characteristics of the uncertain parameters involved in the analysis are presented. The "Analysis Results" section presents the results of the reliability analysis, the implied reliability levels associated with the currently-used threshold FPRs and development of the empirical relationship between FPR and the probability of burst. Two illustrate examples are employed to illustrate the application of the relationship between FPR and the probability of burst to achieve reliability-consistent corrosion mitigation, followed by discussion and conclusions.

\section{Design of Gas Pipelines per CSA Z662}


The design criterion for steel gas transmission pipelines prescribed in CSA Z662-11 can be generally summarized as follows:

$$
\mathrm{UF}=\frac{P_{d} D}{2 \cdot t_{n} \cdot \mathrm{SMYS}} \leq F \cdot L
$$

where UF is defined as the utilization factor in this study but is often referred to as the "\%SMYS" factor in practice (Kariyawasam and Huang 2014); $t_{n}$ is the nominal pipe wall thickness; $P_{d}$ is the design pressure; $D$ is the nominal pipe outside diameter; SMYS is the specified minimum yield strength of the pipe steel; $F$ is the design factor and equals 0.8 , and $L$ is the location factor that depends on the class location of the pipeline. Because the actual pipe outside diameter typically equals the nominal outside diameter with negligible uncertainty (CSA 2011), no distinction is made between these two quantities and a single notation $D$ for the pipe outside diameter is used throughout the paper.

The class location characterizes the population density in the vicinity of the pipeline. There are four class location designations, namely Classes 1, 2, 3 and 4, for gas pipelines. The population density increases as the class location increases, with Class 1 representing sparsely populated areas and Class 4 representing high population density areas such as city centres (CSA 2011). For pipelines that transport non-sour natural gas and are not near roads or railways (which is the most common scenario), $L$ equals $1.0,0.9,0.7$ and 0.55 for Classes 1,2 , 3 and 4 , respectively. It follows that the product of $F$ and $L$ equals $0.8,0.72 .0 .56$ and 0.44 for most Classes 1, 2, 3 and 4 gas pipelines, respectively, per CSA Z662-11.

In most cases, UF equals $F \cdot L$. Given UF, $P_{d}, D$ and SMYS, the nominal pipe wall thickness that satisfies the design criterion can be readily determined from Eq. [1]. However, UF is less 
than $F \cdot L$ if $t_{n}$ is governed by the minimum wall thickness requirement resulting from constructability considerations (CSA 2011). The required minimum wall thickness increases with the pipe diameter; for instance, it equals $4.0 \mathrm{~mm}$ for $D=273.1 \mathrm{~mm}$, i.e. nominal pipe size (NPS) 10 inches, and $4.8 \mathrm{~mm}$ for $D=508 \mathrm{~mm}$ (NPS 20) (CSA 2011).

\section{ASME B31G Modified Model and FPR}

Suppose that a metal-loss corrosion defect on a pipeline has been detected and sized by ILI. The nominal burst pressure capacity of the pipeline at the defect, $P_{b n}$, can be evaluated from the following equation based on the ASME B31.8 Modified model:

$$
P_{b n}=\frac{2 t_{n}(\mathrm{SMYS}+68.95)}{D}\left[\frac{1-\frac{0.85 d_{I L I}}{t_{n}}}{1-\frac{0.85 d_{I L I}}{M t_{n}}}\right], \quad \frac{d_{I L I}}{t_{n}} \leq 0.8
$$

$$
M= \begin{cases}\sqrt{1+0.6275 \frac{l_{I L I}^{2}}{D t_{n}}-0.003375 \frac{l_{I L I}^{4}}{\left(D t_{n}\right)^{2}}}, & \frac{l_{I L I}^{2}}{D t_{n}} \leq 50 \\ 3.3+0.032 \frac{l_{I L I}^{2}}{D t_{n}}, & \frac{l_{I L I}^{2}}{D t_{n}}>50\end{cases}
$$

where SMYS + $68.95(\mathrm{MPa})$ (or equivalently SMYS + $10(\mathrm{ksi})$ ) represents the flow stress of the pipe steel; $d_{I L I}$ and $l_{I L I}$ are the maximum depth (the defect typically has an irregular through-thickness profile with varying depths along the profile) and length reported by ILI, respectively, and $M$ is the bulging or Folias factor. It should be noted that the flow stress is an empirical concept used to convert the stress-strain relationship of a strain-hardening elastic-plastic material into an equivalent elastic-perfectly plastic stress-strain relationship (Cosham and Hopkins 2002). While a commonly adopted definition of the flow stress is the average of the yield and tensile strengths, the flow stress is defined as SMYS + 68.95 (MPa) in the B31G Modified model. The adequacy of such a definition, especially for high-grade 
pipe steels, can be a subject of future investigations. As indicated in Eq. [2a], the B31G Modified model is only applicable to defects that are no more than $80 \%$ through the pipe wall thickness. Finally, it is worth mentioning that commonly used ILI tools (e.g. the magnetic flux leakage tool) typically report $d_{I L I}$ as a fraction of $t_{n}$, i.e. $d_{I L I} / t_{n}$, but $l_{I L I}$ as an absolute value.

Let $P_{o}\left(P_{o} \leq P_{d}\right)$ denote the MOP of the pipeline. The FPR associated with the corrosion defect can be simply evaluated as $P_{b n}$ divided by $P_{o}$. It follows from Eq. [1] that FPR can be written as

$$
\mathrm{FPR}=\frac{P_{b n}}{P_{o}}=\frac{(\mathrm{SMYS}+68.95) / \mathrm{SMYS}}{\mathrm{UF}_{a}}\left[\frac{1-\frac{0.85 d_{I L I}}{t_{n}}}{1-\frac{0.85 d_{I L I}}{M t_{n}}}\right], \quad \frac{d_{I L I}}{t_{n}} \leq 0.8
$$

$$
\mathrm{UF}_{a}=\mathrm{UF} \cdot\left(\frac{P_{o}}{P_{d}}\right)=\frac{P_{o} D}{2 \cdot t_{n} \cdot \mathrm{SMYS}}
$$

where $\mathrm{UF}_{a}$ is the "de-facto" utilization factor of the pipeline during operation, which reflects a combination of the safety margin incorporated in the design and any additional safety margin resulting from the pipeline not operating at its full design capacity, i.e. $P_{o}<P_{d}$.

Equation [3] indicates that FPR evaluated from the B31G Modified model depends on $(\mathrm{SMYS}+68.95) / \mathrm{SMYS}, \mathrm{UF}_{a}, d_{I L I} / t_{n}$ and $l_{I L I}$. Because $\mathrm{UF}_{a}$ usually corresponds to the class location, the recommendation in CSA Z662-11 that the threshold FPR be dependent on the class location of the pipeline is justified. Given SMYS, $d_{I L I} / t_{n}$ and $l_{I L I}$, a larger $\mathrm{UF}_{a}$ leads to a lower FPR and a smaller $\mathrm{UF}_{a}$ leads to a higher FPR. It is interesting to evaluate the upper

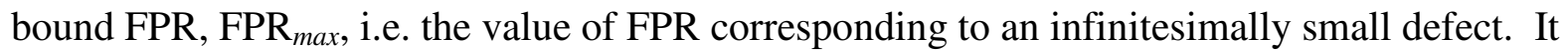
follows from Eq. [3] that $\mathrm{FPR}_{\max }=(\mathrm{SMYS}+68.95) /\left(\mathrm{UF}_{a} \cdot \mathrm{SMYS}\right)$. For commonly used pipe 
steel grades with SMYS ranging from 290 to 483 MPa, i.e. X42 to X70 grades (API 2004), the values of (SMYS+68.95)/SMYS and $\mathrm{FPR}_{\max }$ are listed in Table 1.

\section{Analysis Cases}

We considered a set of 20 representative pipelines corresponding to three diameters $(D=273$ (NPS 10), 406 (NPS 16) and 762 (NPS 30) mm), three SMYS values (SMYS = 289, 359 and $483 \mathrm{MPa})$ and two MOPs $\left(P_{o}=4.0\right.$ and 6.0 MPa). These pipelines cover wide ranges of $t_{n}$ (from 4.0 to $17.9 \mathrm{~mm}$ ) and $\mathrm{UF}_{a}$ (from 0.28 to 0.80 ), as shown in Table 2. Note that cases \#19 and \#20 in the table were selected to represent small-diameter low-pressure pipelines, for which the minimum wall thicknesses requirement (CSA 2011) governs and consequently results in low utilization factors. For each pipeline, a total of 24 representative corrosion defects corresponding to all combinations of four $d_{I L I} / t_{n}$ values $\left(d_{I L I} / t_{n}=0.25,0.35,0.45\right.$ and $0.5)$ and six $l_{I L I}$ values $\left(l_{I L I}=50,100,150,200,300\right.$ and $\left.400 \mathrm{~mm}\right)$ were considered.

\section{Methodology and Input for the Reliability Analysis}

The limit state function for burst of a pipeline at a corrosion defect, $g$, can be written as

$$
g=P_{b} / P-1
$$

where $P_{b}$ is the actual (as opposed to nominal) burst pressure capacity at the defect; $P$ is the internal pressure of the pipeline, and $g \leq 0$ represents failure (i.e. burst). It must be emphasized that $P$ is a random quantity, whereas $P_{d}$ and $P_{o}$ are both nominal pressure parameters. $P_{b}$ is evaluated using the B31G Modified model as follows:

$$
P_{b}=\xi \frac{2 t\left(\sigma_{y}+68.95\right)}{D}\left[\frac{1-\frac{0.85 d}{t}}{1-\frac{0.85 d}{M^{\prime} t}}\right], \quad \frac{d}{t} \leq 0.8
$$




$$
M^{\prime}= \begin{cases}\sqrt{1+0.6275 \frac{l^{2}}{D t}-0.003375 \frac{l^{4}}{(D t)^{2}}}, & \frac{l^{2}}{D t} \leq 50 \\ 3.3+0.032 \frac{l^{2}}{D t}, & \frac{l^{2}}{D t}>50\end{cases}
$$

where $\xi$ is the model error associated with the B31G Modified model; $t$ is the actual pipe wall thickness; $\sigma_{y}$ is the yield strength of the pipe steel, and $d$ and $l$ are the actual maximum depth and length of the corrosion defect, respectively. The probability of failure (burst), $p_{f}$, is given by

$$
p_{f}=\int_{g \leq 0} f_{X}(\boldsymbol{x}) d \boldsymbol{x}
$$

where $f_{X}(x)$ denotes the joint probability density of the random variables involved in the limit state function. The FORM was employed in this study to evaluate the integral in Eq. [6] by calculating the reliability index $\beta$, which is the shortest distance from the origin to the limit state surface in the standard normal space. The probability of burst is then evaluated as $p_{f}=$ $\Phi(-\beta)$, with $\Phi(\bullet)$ being the standard normal distribution function.

Ideally, the time-dependency of the probability of burst should be taken into account because the corrosion defect grows in size with time and the internal pressure of the pipeline also fluctuates with time. Because the corrosion mitigation is typically carried out a relatively short time (say within a year) after ILI, the reliability analysis was simplified as timeindependent in this study. That is, the growth of the corrosion defect was ignored and the internal pressure was assumed to be a time-independent random variable represented by the annual maximum operating pressure. The probability of burst evaluated is therefore with respect to a period of one year. 
The B31G Modified model is applicable for $d / t \leq 0.8$, but the FORM analysis may involve the evaluation of $P_{b}$ corresponding to $0.8<d / t \leq 1$ during the search for the design point or the most probable failure point. To deal with this issue, a simple and practical extension of the B31G Modified model was employed (Zhou and Zhang 2015): $P_{b}$ was assumed to decrease linearly from that calculated using Eq. [6] at $d / t=0.8$ to zero at $d / t=1$.

The statistical information summarized in Annex O of CSA Z662-11 indicates that $t / t_{n}$ generally follows a normal distribution with the mean ranging from 1.0 to 1.01 and the coefficient of variation (COV) ranging from $1.0 \%$ to $1.7 \%$. Therefore, $t / t_{n}$ was assumed to be normally distributed with the mean equal to unity and COV equal to $1.5 \%$ in this study. Jiao et al. (1995) reported that $\sigma_{y} /$ SMYS can be characterized by an either normal or lognormal distribution with the mean ranging from 1.08 to 1.11 and COV ranging from 3.3 to $3.5 \%$ based on statistical analyses of extensive coupon test data. Jiao et al. also suggested that the annual maximum operating pressure for gas pipelines can be characterized by a Gumbel distribution with the mean between $1.03 P_{o}$ and $1.07 P_{o}$, and COV between 1 and $2 \%$. However, it is pointed out in Annex O of CSA Z662-11 that this distribution is applicable to locations immediately downstream of a compressor station. Because the pressure drops along the pipeline between compressor stations, this distribution is a conservative estimate of the annual maximum operating pressure at locations further downstream of a compressor station. It is further indicated in Annex O of CSA Z662-11 that the annual maximum operating pressure of gas pipelines follows a beta distribution with the mean equal to $0.993 P_{o}$ and $\mathrm{COV}$ equal to $3.4 \%$ based on pressure records from one pipeline operator. In this study, $\sigma_{y} / \mathrm{SMYS}$ was assumed to follow a lognormal distribution with the mean equal to 1.1 and COV equal to 
$3.5 \%$, and $P / P_{o}$ was assumed to follow a Gumbel distribution with the mean equal to unity and COV equal to $3.0 \%$.

Zhou and Zhang (2015) showed that the model error for the burst pressure capacity model is critically important for evaluating the probability of burst of pipelines containing corrosion defects. Zhou and Huang (2012) evaluated the model errors associated with eight wellknown burst pressure capacity models for corroded pipes based on 150 full-scale burst tests of pipe segments containing single isolated natural corrosion defects (as opposed to machined defects) collected from the literature. They suggested that the model error for the B31G Modified model be characterized by a Gumbel distribution with the mean and COV equal to 1.297 and $25.8 \%$, respectively. This model error was adopted in this study.

By assuming additive measurement errors (DNV 2010; Zhou and Nessim 2011), the ILIreported defect depth and length are related to the actual defect depth and length, respectively, as follows:

$$
d_{I L I}=d+\varepsilon_{d}
$$

$$
l_{I L I}=l+\varepsilon_{l}
$$

where $\varepsilon_{d}$ and $\varepsilon_{l}$ are the measurement errors associated with the maximum depth and length, respectively. It is common to assume that $\varepsilon_{d}$ and $\varepsilon_{l}$ follow normal distributions with a zero mean (DNV 2010; Zhou and Nessim 2011). The standard deviations of $\varepsilon_{d}$ and $\varepsilon_{l}$ can then be inferred from typical specifications of ILI tools, i.e. $d_{I L I}$ and $l_{I L I}$ within $\pm 10 \% t_{n}$ and $\pm 10 \mathrm{~mm}$ of $d$ and $l$, respectively, $80 \%$ of the time (Stephens and Nessim 2006). Table 3 summarizes the 
probabilistic characteristics of the random variables involved in the reliability analysis. It is assumed that all the random variables are mutually independent of each other.

It is advantageous to write $P_{b} / P$ in the limit state function (i.e. Eq. [5]) in the following form:

$$
P_{b} / P=\xi \frac{\left(\frac{t}{t_{n}}\right)\left(\frac{\sigma_{y}}{S M Y S}+\frac{68.95}{S M Y S}\right)}{\operatorname{UF}_{a}\left(\frac{P}{P_{o}}\right)}\left[\frac{\left(\frac{t}{t_{n}}\right)-0.85\left(\frac{d_{I L I}}{t_{n}}-\frac{\varepsilon_{d}}{t_{n}}\right)}{\left(\frac{t}{t_{n}}\right)-\frac{0.85}{M^{\prime}}\left(\frac{d_{I L I}}{t_{n}}-\frac{\varepsilon_{d}}{t_{n}}\right)}\right]
$$

Equation [10] suggests that given $d_{I L I} / t_{n}$ and $l_{I L I}$, the probability of burst is largely dependent on $\mathrm{UF}_{a}$ : a larger $\mathrm{UF}_{a}$ leads to a higher probability of burst and a smaller $\mathrm{UF}_{a}$ leads to a lower probability of burst.

\section{Analysis Results}

The values of FPR corresponding to the assumed 24 corrosion defects are plotted against the reliability indices obtained from the FORM analysis in Fig. 1 for an analysis case (case \#8) arbitrarily selected from Table 2 .

Two observations of Fig. 1 are in order. First, there is essentially a one-to-one relationship between FPR and the reliability index (probability of burst) for the pipeline. The reliability index increases monotonically as FPR increases; for example, FPR and $\beta$ equal 1.30 and 2.43, respectively, corresponding to $d_{I L I} / t_{n}=0.45$ and $l_{I L I}=150 \mathrm{~mm}$, and 1.34 and 2.59 , respectively, corresponding to $d_{I L I} / t_{n}=0.35$ and $l_{I L I}=200 \mathrm{~mm}$. There are a few anomalies in the FPR $-\beta$ relationship, if FPRs corresponding to different defects are very close. For example, FPR equals 1.38 for $d_{I L I} / t_{n}=0.25$ and $l_{I L I}=400 \mathrm{~mm}$ with the corresponding $\beta$ equal to 2.67 , whereas FPR equals 1.37 for $d_{I L I} / t_{n}=0.5$ and $l_{I L I}=100 \mathrm{~mm}$ with the corresponding $\beta$ equal to 2.69. Such anomalies, however, can be attributed to the minor numerical inaccuracies 
involved in the FORM analysis and are considered inconsequential. Second, the relationship between FPR and $\beta$ for the pipeline is almost perfectly linear. For the other analysis cases shown in Table 2, the above observations are equally applicable.

The approximately linear relationship between FPR and $\beta$ as demonstrated in Fig. 1 deserves some explanations. To this end, the limit state function given by Eq. [5] is rewritten as follows:

$$
g=\left(\frac{P_{b}}{P_{b n}}\right) /\left(\frac{P}{P_{b n}}\right)-1
$$

The internal pressure $P$ is expressed as $\gamma P_{o}$ ( $\gamma$ is a Gumbel-distributed random variable with the mean equal to unity and COV equal to $3 \%$ as indicated in Table 3 ), whereas $P_{b n}$ equals $\mathrm{FPR} \times P_{o}$. It follows that Eq. [11] is now

$$
g=\frac{\mathrm{FPR}}{\gamma} X-1
$$

where $X=P_{b} / P_{b n}$ is a random variable representing the burst pressure capacity normalized by $P_{b n}$. The burst condition, i.e. $g<0$, is equivalent to $\ln (\mathrm{FPR} \cdot X / \gamma)<0$. The simple Monte Carlo simulation of $X$ was carried out based on the statistics of the basic parameters summarized in Table 3. The results indicated that the lognormal distribution can fit simulated samples of $X$ reasonably well with the COV of $X$ being around $26 \%$. Because the uncertainty in $X$ is much higher than that in $\gamma, \gamma$ is simplified as a deterministic quantity for the purpose of investigating the relationship between FPR and $\beta$. Given the above, $\beta$ can now be obtained as

$$
\beta \approx \frac{\ln \mathrm{FPR}+m_{\ln X}-\ln \gamma}{\sigma_{\ln X}}
$$


where $m_{\ln X}$ and $\sigma_{\ln X}$ are the mean and standard deviation of $\ln X$, respectively. Within the relatively narrow range of FPR values for a given pipeline (e.g. between 1.0 and 1.7 for case \#8, and between 2.5 and 3.6 for case \#19 in Table 2), $\operatorname{lnFPR}$ is an almost linear function of FPR. It then follows that the FPR- $\beta$ relationship is approximately linear.

In each of Figs. 2(a) through 2(h), FPRs are plotted against the corresponding $\beta$ values for all the analysis cases with the same $\mathrm{UF}_{a}$. Figure 2 suggests that, somewhat surprisingly, the above-described two observations about the FPR - $\beta$ relationship for a given pipeline are also applicable to different pipelines with the same $\mathrm{UF}_{a}$, although there is slightly more scatter in the data. That is, the FPR - $\beta$ relationship only depends on $\mathrm{UF}_{a}$ and is independent of the other pipeline attributes such as the diameter, pressure, SMYS and wall thickness. For a given $\mathrm{UF}_{a}$, the following equation is proposed to relate FPR to $\beta$ :

$$
\mathrm{FPR}=a \beta+b
$$

where $a$ and $b$ are coefficients obtained from the simple linear regression analysis. The values of $a$ and $b$ corresponding to different values of $\mathrm{UF}_{a}$ are summarized in Table 4. Also shown in Table 4 is the range of $\beta$ values (and the corresponding range of probabilities of burst) over which Eq. [14] was developed for each $\mathrm{UF}_{a}$, i.e. the range of $\beta$ values corresponding to the 24 corrosion defects considered in the analysis. Implications of these ranges for the practical application are discussed in the next section.

The threshold FPR corresponding to a selected target reliability index, $\beta_{t}$, (or equivalently an allowable probability of burst $p_{f a}$ ) can be readily obtained from Eq. [14] for $\mathrm{UF}_{a}$ values given in Table 4. The threshold FPR for a value of $\mathrm{UF}_{a}$ not given in Table 4 can be determined by a 
linear interpolation of the threshold FPRs corresponding to the two nearest bounding $\mathrm{UF}_{a}$ values given in the table. Furthermore, values of $\beta_{t}$ and $p_{f a}$ implied by the threshold FPRs recommended by ASME B31.8S and CSA Z662-11 were obtained from Eq. [14] and are summarized in Table 5. The results in Table 5 suggest that the threshold FPR of 1.1 recommended by ASME B31.8S leads to relatively low target reliability levels. For pipelines with high class location designations (i.e. high population density in the vicinity of the pipelines) and thus low $\mathrm{UF}_{a}$ values such as 0.56 and 0.44 , the implied target reliability levels appear too low to be commensurate with the potentially severe human safety-related consequences of burst associated with such pipelines (Nessim et al. 2009). On the other hand, the target reliability level implied by the threshold FPR recommended by CSA Z662-11 increases markedly as the class location increases: $\beta_{t}$ increases from 2.26 for Class 1 pipelines $\left(\mathrm{UF}_{a}=0.80\right)$ to 5.02 for Class 4 pipelines $\left(\mathrm{UF}_{a}=0.44\right)$ with the corresponding $p_{f a}$ decreasing by approximately five orders of magnitude from $1.2 \times 10^{-2}$ to $2.6 \times 10^{-7}$. Considering that $p_{f a}$ $=2.6 \times 10^{-7}$ is an extremely low failure probability, the threshold FPR of 2.27 for Class 4 pipelines is perhaps overly stringent. The drawback of the CSA Z662 threshold FPRs, however, is that they are associated with the class location of the pipeline rather than $\mathrm{UF}_{a}$ (Kariyawasam and Huang 2014). Two pipelines with the same class location can have different values of $\mathrm{UF}_{a}$. In this case, applying the same CSA Z662 threshold FPR will lead to different implied reliability levels for the two pipelines. This drawback is overcome by the use of Eq. [14] and Table 4. For example, consider two Class 2 pipelines with $\mathrm{UF}_{a}$ equal to 0.72 and 0.60 , respectively. From Eq. [14] and Table 4, the implied values of $\beta_{t}$ were determined to be $2.75\left(p_{f a}=3.0 \times 10^{-3}\right)$ and $2.65\left(p_{f a}=4.0 \times 10^{-3}\right)$ for $\mathrm{UF}_{a}=0.72$ and 0.60 , 
respectively, corresponding to the CSA Z662 threshold FPR of 1.39. To achieve $\beta_{t}=2.75$ for the pipeline with $\mathrm{UF}_{a}=0.60$, the corresponding threshold FPR should be 1.42 .

\section{Illustrative Examples}

In this section, two hypothetical examples are used to validate Eq. [14] as well as illustrate its application. The first example involves a pipeline with $D=508 \mathrm{~mm}$ (NPS 20), SMYS = 359 $\mathrm{MPa}, P_{o}=7.0 \mathrm{MPa}, t_{n}=6.9 \mathrm{~mm}$ and $\mathrm{UF}_{a}=0.72$. It is assumed that an allowable probability of burst of $1.0 \times 10^{-3}$ (i.e. $\beta_{t}=3.09$ ) is selected for mitigating the defects on the pipeline. The corresponding threshold FPR is then determined as 1.48 from Eq. [14]. Consider three representative corrosion defects with FPRs equal to the threshold FPR of 1.48. The ILIreported depths and lengths of these defects are summarized in Table 6. The probabilities of burst of the three defects were evaluated using the FORM based on the same statistical information as summarized in Table 3 and are shown in Table 6. As the probabilities of burst associated with all three defects are slightly $(10-15 \%)$ below $1.0 \times 10^{-3}$, the results demonstrate the validity and simplicity of using Eq. [14] to achieve reliability-consistent mitigation of corrosion defects.

The second example involves a pipeline with $D=609.6 \mathrm{~mm}(\mathrm{NPS} 24), \mathrm{SMYS}=448 \mathrm{MPa}, P_{o}$ $=6.8 \mathrm{MPa}, t_{n}=7.1 \mathrm{~mm}$ and $\mathrm{UF}_{a}=0.65$. An allowable probability of burst of $5.0 \times 10^{-4}$ (i.e. $\left.\beta_{t}=3.29\right)$ was assumed for the defect mitigation. The corresponding threshold FPR was calculated to be 1.56 by linearly interpolating the FPR values corresponding to $\beta_{t}=3.29$ for $\mathrm{UF}_{a}=0.72$ and 0.60 , respectively. Consider three representative corrosion defects that have FPRs equal to 1.56. The ILI-reported depths and lengths of the defects as well as the probabilities of burst associated with the defects are also shown in Table 6. As indicated in 
the table, the three probabilities of burst are about $15-20 \%$ below $5.0 \times 10^{-4}$, which again demonstrates the validity of Eq. [14].

\section{Discussion}

The FPRs corresponding to the set of 24 corrosion defects included in the analysis are representative of FPRs for the corrosion defects found in practice. As such, the ranges of $\beta$ values given in Table 4 are representative for the corresponding values of $\mathrm{UF}_{a}$. Although Eq. [14] can be extrapolated to $\beta$ values beyond the ranges given in Table 4 , the extrapolation may result in threshold FPRs that are either impractical or non-governing. For example, a $\beta_{t}$ of $3.5\left(p_{f a}=2.3 \times 10^{-4}\right)$ for $\mathrm{UF}_{a}=0.80$, which is greater than the upper bound of the corresponding $\beta$ range given in Table 4, results in a threshold FPR of 1.55. This threshold FPR is clearly impractical for pipelines with $\mathrm{UF}_{a}=0.80$ and $\mathrm{SMYS} \geq 290 \mathrm{MPa}$ (i.e. X42), as the corresponding values of $\mathrm{FPR}_{\max }$ are all less than or equal to 1.55 (see Table 1). On the other hand, a $\beta_{t}$ of $3.0\left(p_{f a}=1.4 \times 10^{-3}\right)$ for $\mathrm{UF}_{a}=0.44$, which is smaller than the lower bound of the corresponding $\beta$ range, results in a threshold FPR of 1.51. If this threshold FPR is applied to case $\# 18\left(D=762 \mathrm{~mm}, \mathrm{SMYS}=483 \mathrm{MPa}\right.$ and $\left.t_{n}=10.8 \mathrm{~mm}\right)$ in Table 2, any corrosion defects with $d_{I L I} / t_{n}<0.76$ and $l_{I L I}<150 \mathrm{~mm}$ will be considered non-critical as the corresponding FPRs are greater than 1.51. In practice, however, most pipeline operators will mitigate defects with $d_{I L I} / t_{n}>0.60-0.70$ regardless of their FPRs (Kariyawasam and Huang 2014). Such a practice may also dictate the mitigation of defects on pipelines governed by the minimum wall thickness requirement, e.g. the cases with $\mathrm{UF}_{a}=0.35$ and 0.28 in Table 2, unless a high target reliability level (e.g. $\beta_{t}>4.0$ ) is justified for such pipelines. 
It must be emphasized that Eq. [14] and Table 4 are valid for a particular burst pressure capacity model, i.e. the ASME B31G Modified model, and a specific set of input in the reliability analysis as summarized in Table 3. A re-evaluation of the FPR- $\beta$ relationship is needed, if a different burst pressure capacity model, e.g. the ASME B31G or PCORRC model, is employed to determine FPR and/or if the probabilistic characteristics of $t / t_{n}, \sigma_{y} / \mathrm{SMYS}$, $P / P_{o}, \varepsilon_{d}$ and $\varepsilon_{l}$ for a specific pipeline deviate from those summarized in Table 3 to the extent that the use of Eq. [14] and Table 4 results in significantly non-conservative threshold FPRs.

\section{Conclusions}

This study investigated the relationship between FPR and the probability of burst for metalloss corrosion defects on natural gas transmission pipelines designed per CSA Z662-11. The ASME B31G Modified model was employed to evaluate the burst pressure capacity of the pipeline at the corrosion defect. A set of 20 representative gas pipelines with different diameters, maximum operating pressure and steel grades were developed, corresponding to wide ranges of the pipe wall thickness and utilization factor $\left(\mathrm{UF}_{a}\right)$. For each pipeline, FPRs for 24 representative corrosion defects with $d_{I L I} / t_{n}$ ranging from 0.25 to 0.5 and $l_{I L I}$ ranging from 50 to $400 \mathrm{~mm}$ were evaluated using the B31G Modified model. Furthermore, the FORM was employed to evaluate the probability of burst of the pipeline at each of the 24 corrosion defects by taking into account uncertainties in the wall thickness, yield strength and internal pressure, measurement errors associated with the ILI-reported defect sizes, and the model error associated with the B31G Modified model.

The analysis results suggest that a unique linear relationship exists between FPR and the reliability index $(\beta)$ corresponding to the probability of burst for different pipelines with the 
same utilization factor. Simple linear regression equations between FPR and $\beta$ for different utilization factors were then developed on the basis of the analysis results. These equations allow rapid determination of the threshold FPR corresponding to a given target reliability level for the purpose of identifying critical defects, thus achieving reliability-consistent mitigation of corrosion defects on pipelines. Two examples were used to illustrate the application and validity of the developed equations. The implied reliability levels associated with the threshold FPRs recommended by ASME B31.8S and CSA Z662-11 were also clarified based on the FPR - $\beta$ equations developed. It is observed that the ASME B31.8S threshold FPR implies relatively low reliability levels, especially for pipelines with high class location designations, whereas the reliability levels implied by the CSA Z662 threshold FPRs increase markedly as the class location increases. Finally, it is emphasized that the application of the proposed FPR - $\beta$ equation to a specific pipeline is predicated on the $\mathrm{B} 31 \mathrm{G}$ Modified model as well as the condition that the probabilistic characteristics of the relevant random variables for the pipeline do not deviate markedly from those assumed in this study.

\section{Acknowledgement}

The authors gratefully acknowledge the financial support provided by TransCanada Pipelines Ltd. and the Natural Sciences and Engineering Research Council of Canada (NSERC) in the form of a Collaborative Research and Development project (CRDPJ 470571-14). Helpful comments from the two anonymous reviewers are appreciated. 


\section{References}

American Petroleum Institute (API). 2004. API Specification 5L: specification for line pipe. American Petroleum Institute, Washington, D.C.

American Society of Mechanical Engineers (ASME). 2010. ASME B31.8S-2010: Managing system integrity of gas pipelines. ASME Code for Pressure Piping, B31 Supplement to ASME B31.8. American Society of Mechanical Engineers, New York.

Bartlett, F. M., Hong, H. P. and Zhou, W. 2003. Load factor calibration for the proposed 2005 edition of the National Building Code of Canada: companion action load combination. Canadian Journal of Civil Engineering, 30: 440-448.

Cosham, A. and Hopkins, P. 2002. The pipeline defect assessment manual. In Proceedings of the $4^{\text {th }}$ International Pipeline Conference, Calgary, 29 Sept - 3 Oct 2002, American Society of Mechanical Engineers, IPC2002-27067.

Canadian Standards Association (CSA). 2011. CSA Z662: Oil and gas pipeline systems. Canadian Standards Association, Mississauga, Ontario.

Det Norske Veritas (DNV). 2010. DNV RP-F101, Corroded pipelines. DNV Recommended Practice. Det Norske Veritas, Hovik, Norway.

Jiao G., Sotberg T., and Igland R. T. 1995. SUPERB 2M statistical data-basic uncertainty measures for reliability analysis of offshore pipelines. SUPERB JIP Report No. STF70F95212, Norwegian Marine Technology Research Institute, Trondheim, Norway. 
Kariyawasam, S. and Huang, T. 2014. How safe failure pressure ratios are related to \%SMYS. In Proceedings of the $10^{\text {th }}$ International Pipeline Conference, Calgary, 29 Sept - 3 Oct 2014, American Society of Mechanical Engineers, IPC2014-33647.

Kiefner, J. F. and Vieth, P. H. 1989. A modified criterion for evaluating the remaining strength of corroded pipe. PR 3-805, American Gas Association, Washington, D.C.

Low, B. K. and Tang, W. H. 1997. Efficient reliability evaluation using spreadsheet. Journal of Engineering Mechanics, ASCE, 123(7): 749-752.

Low, B. K. and Tang, W. H. 2007. Efficient spreadsheet algorithm for first-order reliability method. Journal of Engineering Mechanics, ASCE, 133(12): 1378-1387.

Melchers, R. E. 1999. Structural reliability: analysis and prediction, 2nd Ed. John Wiley \& Sons, Chichester, England.

Nessim, M. A., Zhou, W., Zhou, J., Rothwell, B. and McLamb, M. 2009. Target reliability levels for design and assessment of onshore natural gas pipelines. Journal of Pressure Vessel Technology, ASME, 131(6): 061701, 1-12.

Nowak, A.S. 1995. Calibration of LRFD bridge code. Journal of Structural Engineering, ASCE, 121(8): 1245-1251.

Stephens, M. and Nessim, M. A. 2006. Comprehensive approach to corrosion management based on structural reliability methods. In Proceedings of 6th International Pipeline Conference, Calgary, 25 - 29 Sept 2006, American Society of Mechanical Engineers, IPC2006-10458. 
Zhou, W. and Zhang, S. 2015. Impact of model errors of burst capacity models on the reliability evaluation of corroding pipelines. Journal of Pipeline Systems Engineering and Practice, DOI: 10.1061/(ASCE)PS.1949-1204.0000210, 04015011, 1-11.

Zhou, W. and Huang, G.X. 2012. Model error assessments of burst capacity models for corroded pipelines. International Journal of Pressure Vessels and Piping, 99-100: 1-8.

Zhou, W. and Nessim, M.A. 2011. Optimal deign of onshore natural gas pipelines. Journal of Pressure Vessel Technology, ASME, 133(3): 031702, 1-11. 
Table 1 Values of FPR ${ }_{\text {max }}$ for different pipe steel grades

\begin{tabular}{|c|c|c|c|c|c|c|}
\hline \multicolumn{2}{|c|}{ Steel Grade } & $\mathrm{X} 42$ & X52 & X60 & X65 & $\mathrm{X} 70$ \\
\hline \multicolumn{2}{|c|}{ SMYS (MPa) } & 290 & 359 & 413 & 448 & 483 \\
\hline \multicolumn{2}{|c|}{$(\mathrm{SMYS}+68.95) / \mathrm{SMYS}$} & 1.24 & 1.19 & 1.17 & 1.15 & 1.14 \\
\hline \multirow{4}{*}{$\mathrm{FPR}_{\max }$} & $\mathrm{UF}_{a}=0.8$ & 1.55 & 1.49 & 1.46 & 1.44 & 1.43 \\
\hline & $\mathrm{UF}_{a}=0.72$ & 1.72 & 1.65 & 1.63 & 1.60 & 1.58 \\
\hline & $\mathrm{UF}_{a}=0.56$ & 2.21 & 2.13 & 2.09 & 2.05 & 2.04 \\
\hline & $\mathrm{UF}_{a}=0.44$ & 2.82 & 2.70 & 2.66 & 2.61 & 2.59 \\
\hline
\end{tabular}


Table 2 Attributes of representative pipelines considered in the analysis

\begin{tabular}{cccccc}
\hline $\begin{array}{c}\text { Case } \\
\text { No. }\end{array}$ & $\begin{array}{c}P_{o} \\
(\mathrm{MPa})\end{array}$ & $\begin{array}{c}\text { SMYS } \\
(\mathrm{MPa})\end{array}$ & $\begin{array}{c}D \\
(\mathrm{~mm})\end{array}$ & $\begin{array}{c}t_{n} \\
(\mathrm{~mm})\end{array}$ & $\mathrm{UF}_{a}$ \\
\hline 1 & 6 & 290 & 762 & 9.9 & 0.80 \\
\hline 2 & 6 & 290 & 762 & 10.9 & 0.72 \\
\hline 3 & 6 & 290 & 762 & 13.1 & 0.60 \\
\hline 4 & 6 & 290 & 762 & 14.1 & 0.56 \\
\hline 5 & 6 & 290 & 762 & 15.8 & 0.50 \\
\hline 6 & 6 & 290 & 762 & 17.9 & 0.44 \\
\hline 7 & 6 & 359 & 762 & 8.0 & 0.80 \\
\hline 8 & 6 & 359 & 762 & 8.8 & 0.72 \\
\hline 9 & 6 & 359 & 762 & 10.6 & 0.60 \\
\hline 10 & 6 & 359 & 762 & 11.4 & 0.56 \\
\hline 11 & 6 & 359 & 762 & 12.7 & 0.50 \\
\hline 12 & 6 & 359 & 762 & 14.5 & 0.44 \\
\hline 13 & 6 & 483 & 762 & 5.9 & 0.80 \\
\hline 14 & 6 & 483 & 762 & 6.6 & 0.72 \\
\hline 15 & 6 & 483 & 762 & 7.9 & 0.60 \\
\hline 16 & 6 & 483 & 762 & 8.5 & 0.56 \\
\hline 17 & 6 & 483 & 762 & 9.5 & 0.50 \\
\hline 18 & 6 & 483 & 762 & 10.8 & 0.44 \\
\hline 19 & 4 & 483 & 273 & 4.0 & 0.28 \\
\hline 20 & 4 & 483 & 406 & 4.8 & 0.35 \\
\hline & & & & &
\end{tabular}


Table 3 Probabilistic characteristics of random variables in the reliability analysis

\begin{tabular}{ccccc}
\hline Variable & Distribution & Mean & COV $(\%)$ & Source \\
\hline$t / t_{n}$ & Normal & 1.0 & 1.5 & CSA (2011) \\
\hline$\sigma_{y} /$ SMYS & Lognormal & 1.1 & 3.5 & Jiao et al. (1995) \\
\hline$P / P_{o}$ & Gumbel & 1.0 & 3.0 & $\begin{array}{c}\text { Jiao et al. (1995) } \\
\text { CSA (2011) }\end{array}$ \\
\hline$\varepsilon_{d}\left(\% t_{n}\right)$ & Normal & 0 & $7.8^{1}$ & Stephens \& Nessim (2006) \\
\hline$\varepsilon_{l}(\mathrm{~mm})$ & Normal & 0 & $7.8^{1}$ & Stephens and Nessim (2006) \\
\hline$\xi$ & Gumbel & 1.297 & 25.8 & Zhou and Huang (2012) \\
\hline
\end{tabular}

1 . The values are standard deviations. 
Table 4. Regression coefficients in the FPR - $\beta$ relationship for different values of $\mathrm{UF}_{a}$

\begin{tabular}{ccccc}
\hline $\mathrm{UF}_{a}$ & $a$ & $b$ & Range of $\beta$ & Range of $p_{f}$ \\
\hline 0.80 & 0.242 & 0.704 & {$[1.24,3.29]$} & {$\left[5.0 \times 10^{-4}, 1.1 \times 10^{-1}\right]$} \\
\hline 0.72 & 0.257 & 0.683 & {$[1.28,3.78]$} & {$\left[7.8 \times 10^{-5}, 1.0 \times 10^{-1}\right]$} \\
\hline 0.60 & 0.292 & 0.617 & {$[2.05,4.69]$} & {$\left[1.4 \times 10^{-6}, 2.0 \times 10^{-2}\right]$} \\
\hline 0.56 & 0.308 & 0.578 & {$[2.38,5.05]$} & {$\left[2.2 \times 10^{-7}, 8.7 \times 10^{-3}\right]$} \\
\hline 0.50 & 0.338 & 0.500 & {$[2.87,5.60]$} & {$\left[1.1 \times 10^{-8}, 2.0 \times 10^{-3}\right]$} \\
\hline 0.44 & 0.377 & 0.377 & {$[3.44,6.17]$} & {$\left[3.4 \times 10^{-10}, 2.9 \times 10^{-4}\right]$} \\
\hline 0.35 & 0.406 & 0.360 & {$[4.03,6.55]$} & {$\left[2.9 \times 10^{-11}, 2.8 \times 10^{-5}\right]$} \\
\hline 0.28 & 0.479 & 0.156 & {$[4.74,7.29]$} & {$\left[1.6 \times 10^{-13}, 1.1 \times 10^{-6}\right]$} \\
\hline
\end{tabular}


Table 5. Target reliability levels $\left(\beta_{t}\right.$ and $\left.p_{f a}\right)$ implied by threshold FPRs recommended by ASME B31.8S and CSA Z662-11

\begin{tabular}{ccccc}
\hline Standard & Threshold FPR & $\mathrm{UF}_{a}$ & $\beta_{t}$ & $p_{f a}$ \\
\hline \multirow{2}{*}{ ASME } & 1.1 & $0.72^{1}$ & 1.62 & $5.3 \times 10^{-2}$ \\
\cline { 2 - 5 } B31.8S & 1.1 & 0.56 & $1.69^{2}$ & $4.6 \times 10^{-2}$ \\
\cline { 2 - 5 } & 1.1 & 0.44 & $1.92^{2}$ & $2.7 \times 10^{-2}$ \\
\hline \multirow{3}{*}{ CSA } & 1.25 & 0.80 & 2.26 & $1.2 \times 10^{-2}$ \\
\cline { 2 - 5 } Z662-11 & 1.39 & 0.72 & 2.75 & $3.0 \times 10^{-3}$ \\
\cline { 2 - 5 } & 1.79 & 0.56 & 3.94 & $4.1 \times 10^{-5}$ \\
\cline { 2 - 5 } & 2.27 & 0.44 & 5.02 & $2.6 \times 10^{-7}$ \\
\hline
\end{tabular}

Note: 1. Pipelines designed per the ASME standard typically have a maximum utilization factor of 0.72 .

2. The value of $\beta_{t}$ is beyond the range of $\beta$ values indicated in Table 4 . 
Table 6. Probabilities of burst of corrosion defects in Examples 1 and 2

\begin{tabular}{|c|c|c|c|c|c|}
\hline Example & Defect & $d_{I L I} / t_{n}$ & $l_{I L I}(\mathrm{~mm})$ & FPR & $p_{f}$ \\
\hline \multirow{3}{*}{1} & 1 & 0.49 & 50 & \multirow{3}{*}{1.48} & $9.0 \times 10^{-4}$ \\
\hline & 2 & 0.34 & 75 & & $8.5 \times 10^{-4}$ \\
\hline & 3 & 0.27 & 100 & & $8.8 \times 10^{-4}$ \\
\hline \multirow{3}{*}{2} & 1 & 0.58 & 50 & \multirow{3}{*}{1.56} & $4.3 \times 10^{-4}$ \\
\hline & 2 & 0.42 & 75 & & $4.2 \times 10^{-4}$ \\
\hline & 3 & 0.33 & 100 & & $4.0 \times 10^{-4}$ \\
\hline
\end{tabular}




\section{Figure Captions}

Figure 1. FPR vs. Reliability Index for Case $\# 8\left(D=762 \mathrm{~mm}, P_{o}=6 \mathrm{MPa}, \mathrm{SMYS}=359 \mathrm{MPa}\right.$, $t_{n}=8.8 \mathrm{~mm}$ and $\left.\mathrm{UF}_{a}=0.72\right)$

Figure 2. FPR vs. Reliability Index for Analysis Cases with the Same $\mathrm{UF}_{a}$
(a) $\mathrm{UF}_{a}=0.80$
(b) $\mathrm{UF}_{a}=0.72$
(c) $\mathrm{UF}_{a}=0.60$
(d) $\mathrm{UF}_{a}=0.56$
(e) $\mathrm{UF}_{a}=0.50$
(f) $\mathrm{UF}_{a}=0.44$
(g) $\mathrm{UF}_{a}=0.35$
(h) $\mathrm{UF}_{a}=0.28$ 


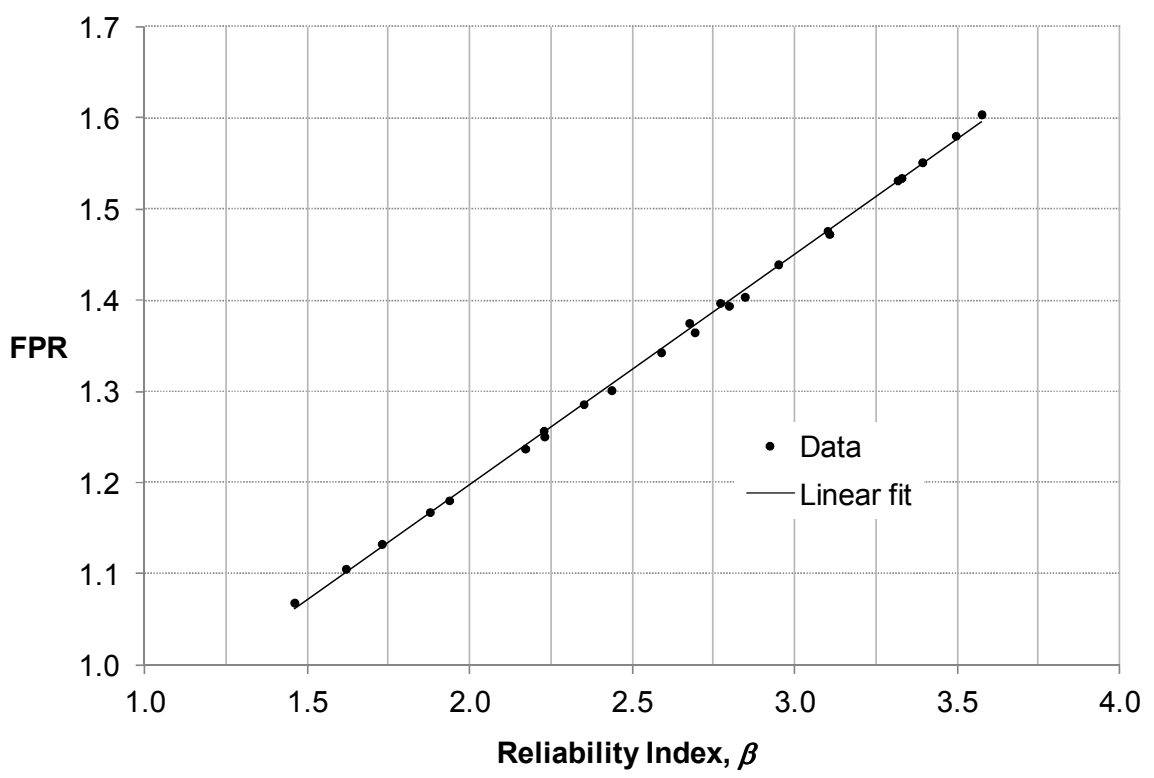

https://mc06.manuscriptcentral.com/cjce-pubs 


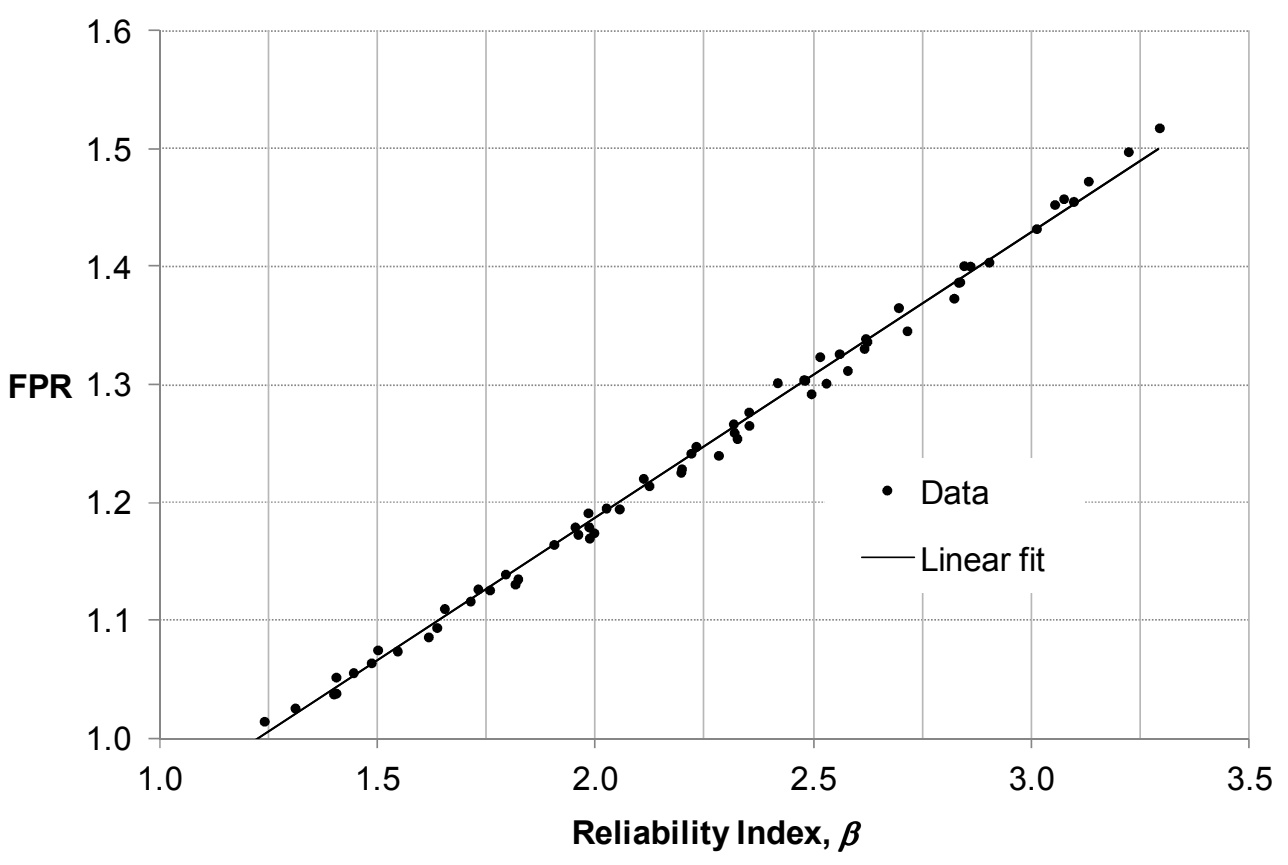

https://mc06.manuscriptcentral.com/cjce-pubs 


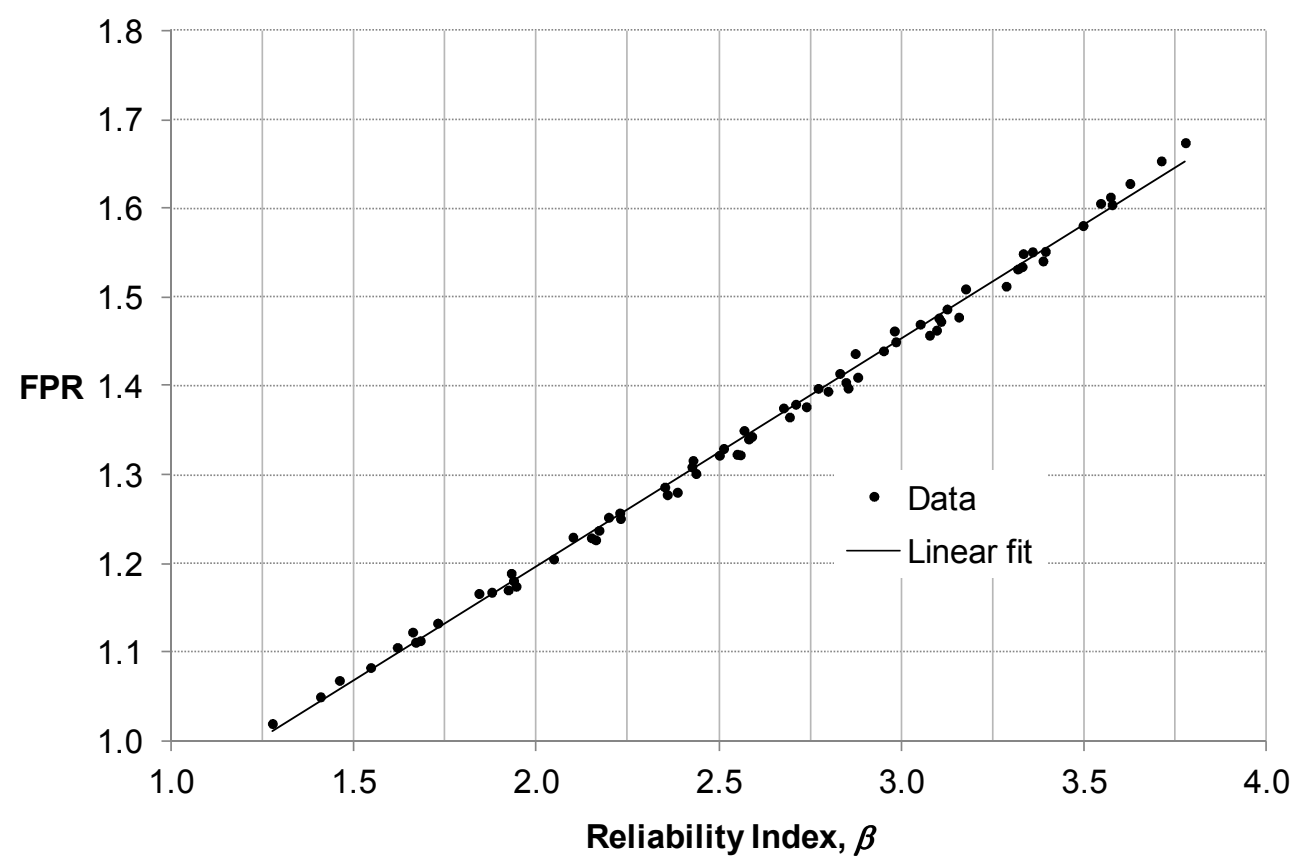

https://mc06.manuscriptcentral.com/cjce-pubs 


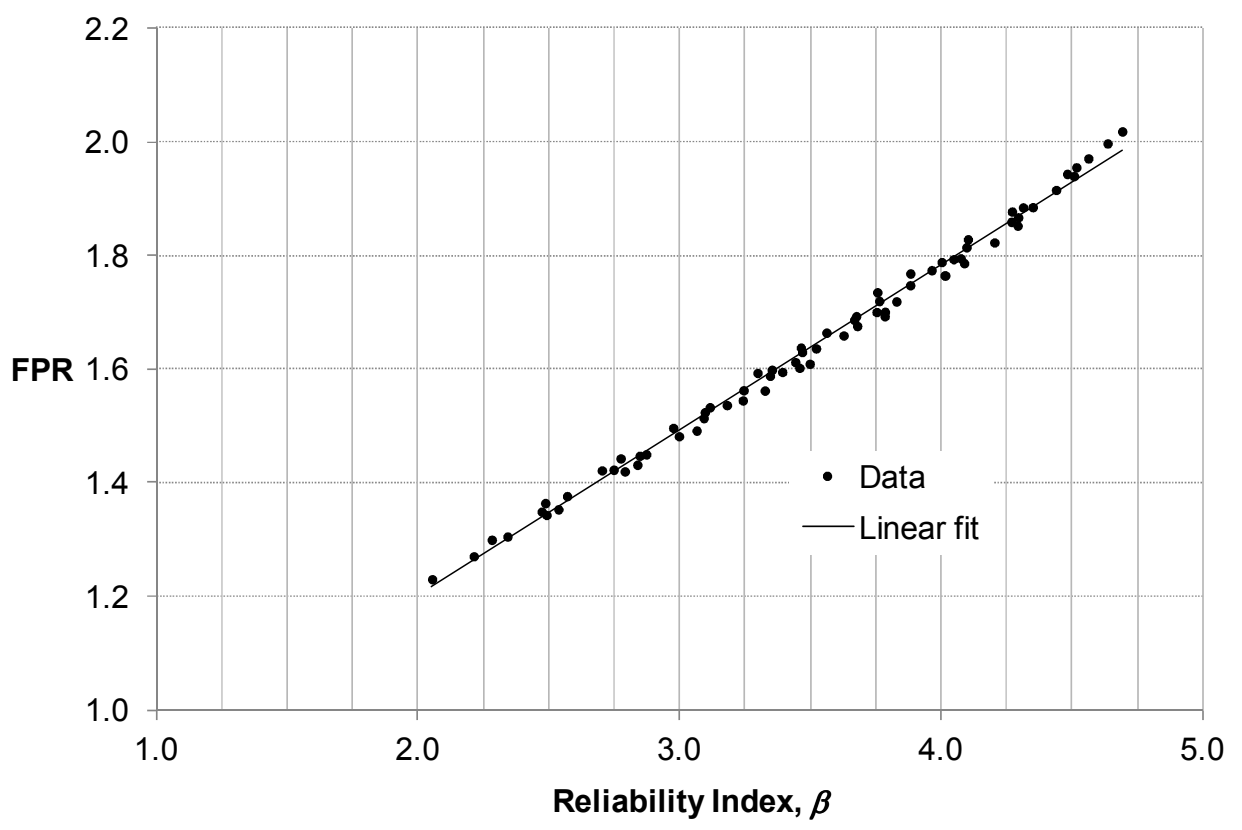

https://mc06.manuscriptcentral.com/cjce-pubs 


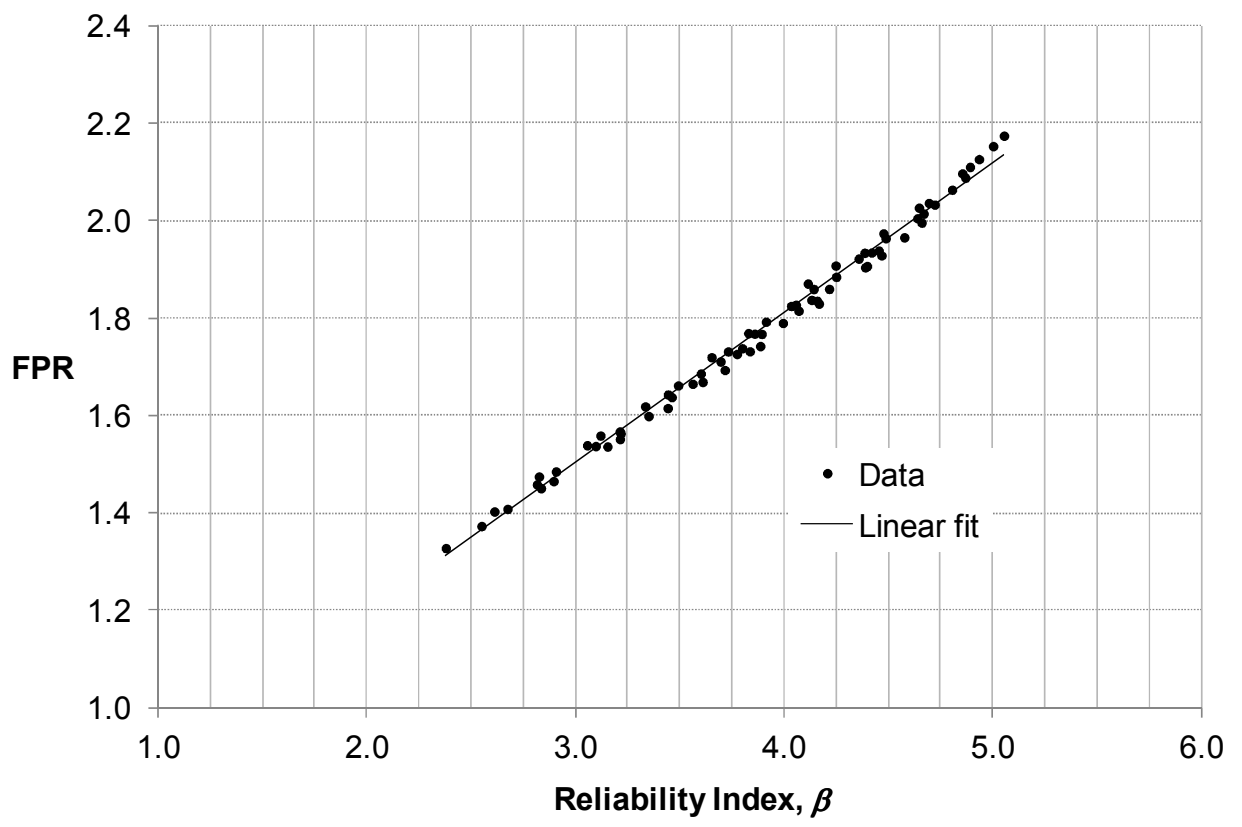

https://mc06.manuscriptcentral.com/cjce-pubs 


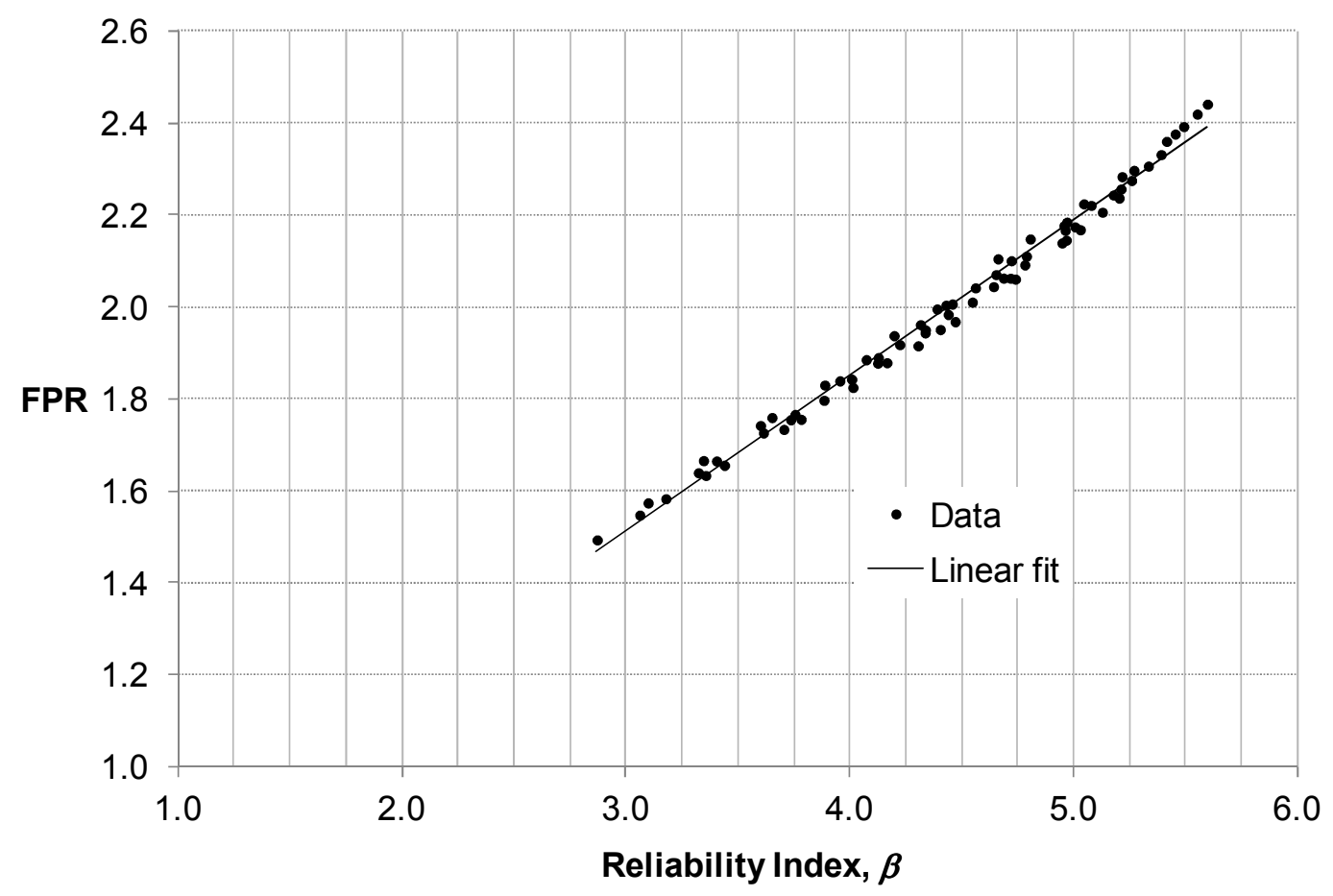




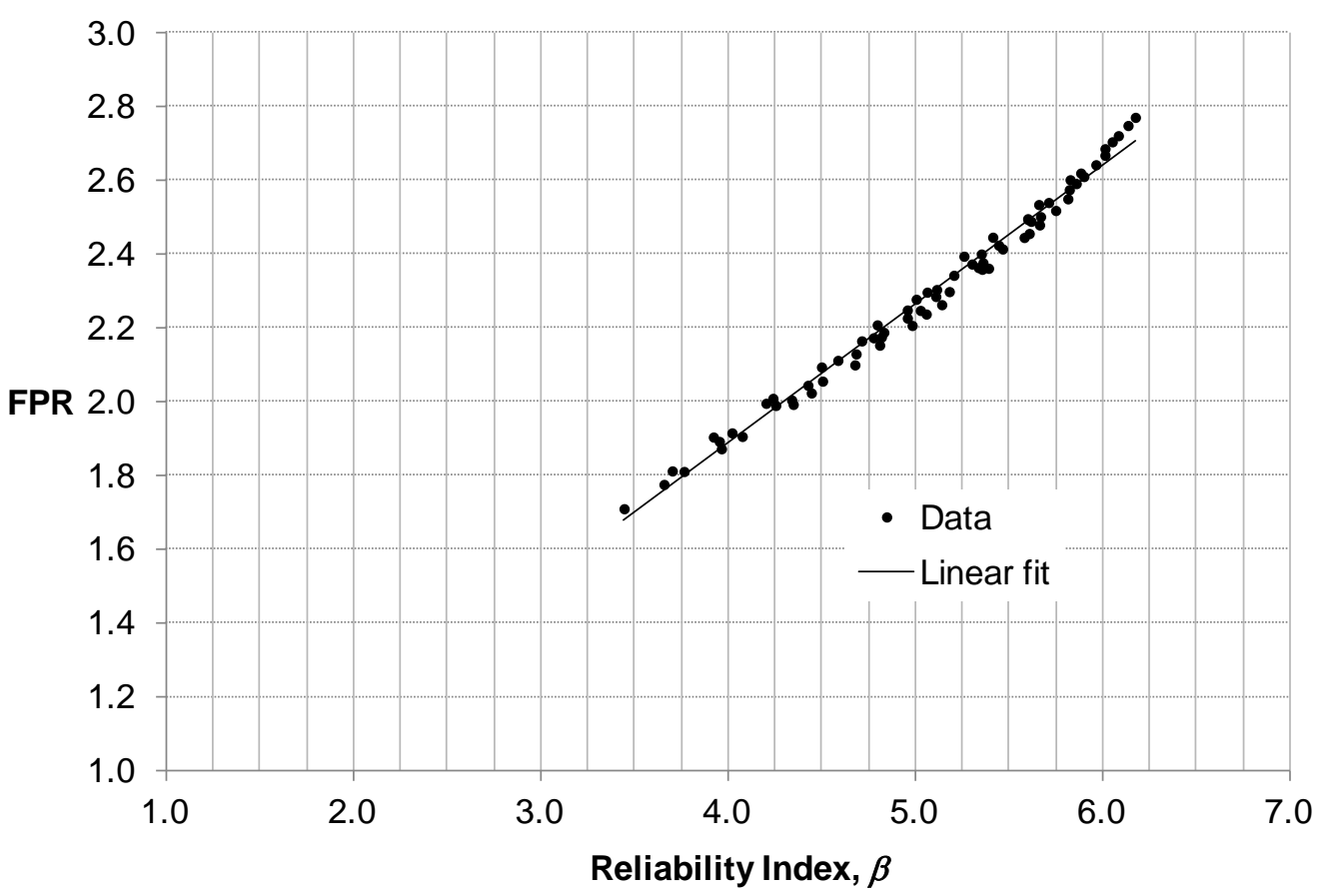

https://mc06.manuscriptcentral.com/cjce-pubs 


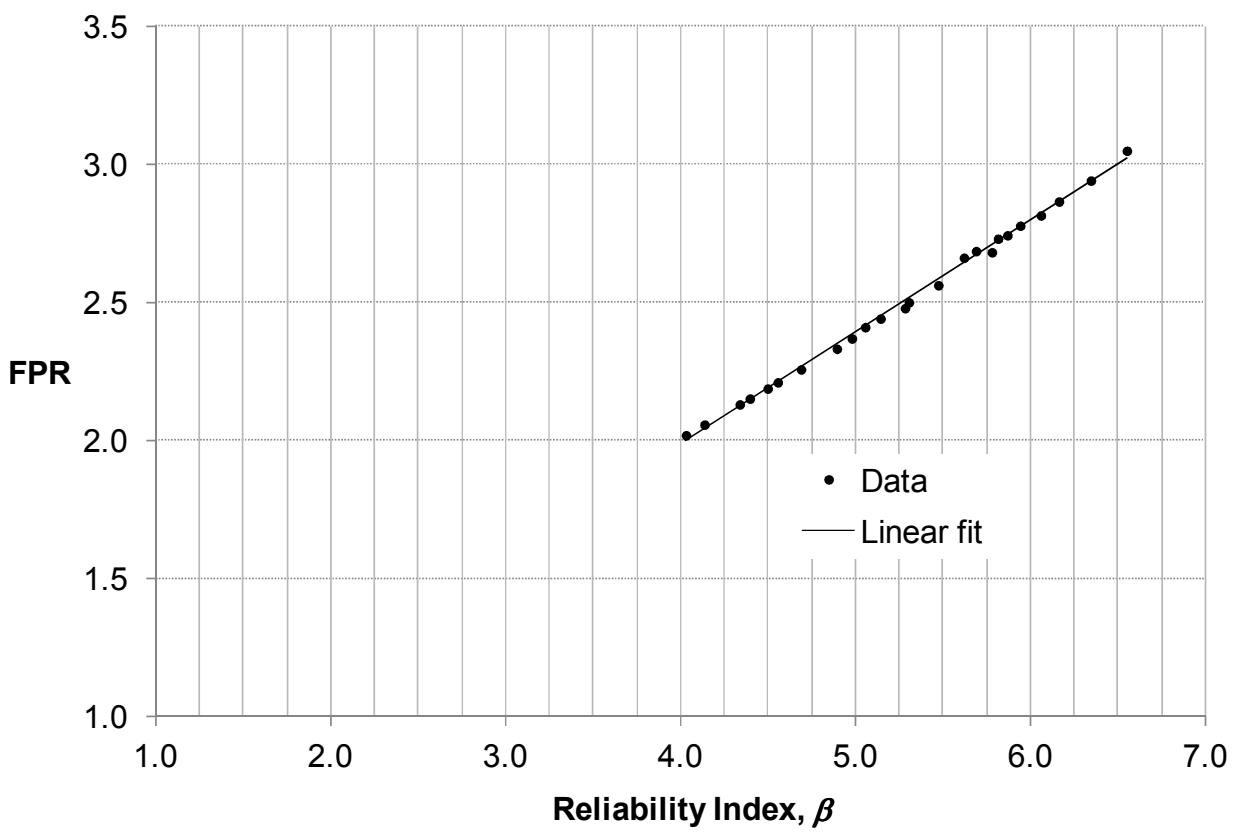

https://mc06.manuscriptcentral.com/cjce-pubs 


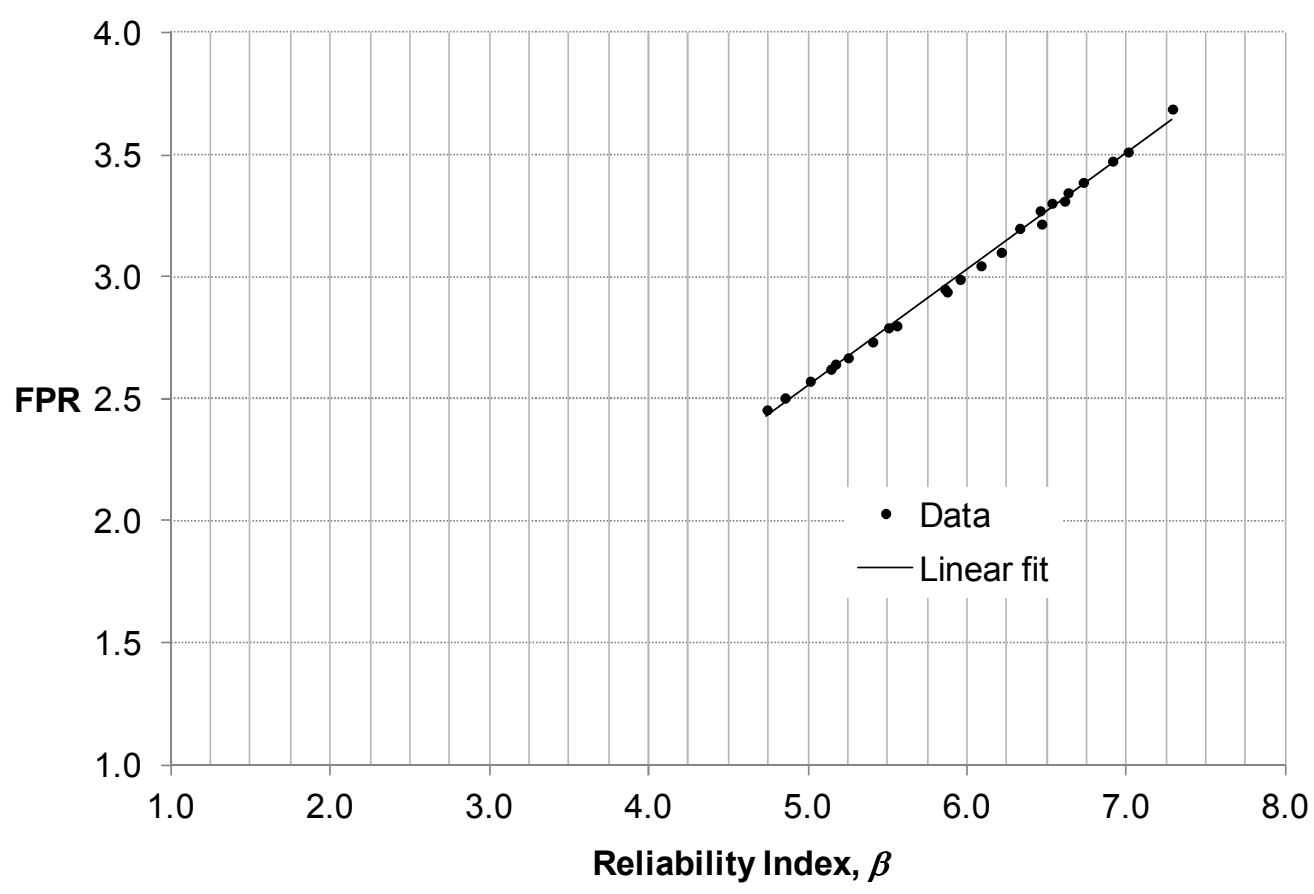

https://mc06.manuscriptcentral.com/cjce-pubs 